http://jmscr.igmpublication.org/home/

ISSN (e)-2347-176x ISSN (p) 2455-0450

crossref DOI: https://dx.doi.org/10.18535/jmscr/v7i8.108

Journal Of Medical Science And Clinical Research

Original Article

\title{
A Retrospective Analysis of the Surgical Treatment Options for Sacrococcygeal Pilonidal Sinus, with Special Reference to Limberg Flap
}

\author{
Author \\ Arun.S \\ Assistant Professor ${ }^{1}$, Department of General Surgery, Government Medical College Manjeri, Kerala \\ Corresponding Author \\ Dr Arun.S \\ Assistant Professor, Department of General Surgery, Government Medical College, Manjeri, Kerala, \\ India-676121
}

\begin{abstract}
.
Introduction: Pilonidal sinus (PNS) is a vexing problem for a individual. PNS is blind ending track lined with granulation tissue leading to a cystic cavity containing bits and pieces of hair.

Aim: To observe and analyse the surgical treatment options for sacrococcygeal pilonidal sinus with a special reference to limberg flap.

Material and Methods: The patients presenting with PNS to the general surgery department at a tertiary care centre in north Malabar, Kerala for two years from 2016 were included in this study. All PNS without abscess formation were treated with limberg flap, Z plasty or wide local excision. Those with abscess formation, I\&D was done primarily. Later after the abscess healed, wide local excision and healing with secondary intention was followed.

Results: 39 cases of sacrococcygeal PNS were included in this study. Karydakis and Bascom method methods were not used. There was single recurrence each after wide excision and limberg flap and 2 after $Z$ plasty in sacrococcygeal pilonidal sinus.

Conclusion: Sacrococcygeal pilonidal sinus is a vexing problem. The changes in the hormonal balance during puberty is the triggering factor. Many treatment modalities are in the offering, suggesting that a complete cure may not be possible with any of those available. Wide local excision with primary closure with Limberg flap or Z plasty or wide local exciion with healing by secondary intention are viable options for this condition.

Keywords: Infection, Limberg flap, Pilonidal sinus, Sacrococcygeal sinus, Wide local excision, Z plasty.
\end{abstract}

\section{Introduction}

Sacrococcygeal pilonidal sinus(PNS) is a vexing problem for a individual. PNS is blind ending track lined with granulation tissue leading to a cystic cavity containing bits and pieces of hair. ${ }^{[1]}$ They are commonly found in the sacro coccygeal area, axilla, inter digital clefts, umbilicus, penis, clitoris and in the inter mammary area. ${ }^{[2]}$ The mean age of occurrence is 15-40 years, with a male predominance. ${ }^{[3,4]}$ The growth hormones after puberty, plays an important role in the development of this condition. ${ }^{[5]}$ The congenital and acquired theories of PNS tries to explain the evolvement of it. The hair follicle swells up due to keratin deposition and this leads to peri folliculitis 
which ruptures into the subcutaneous tissue in the midline or open up laterally leading to the formation of the PNS. ${ }^{[6]}$ When the micro organisms harbour the area, abscess develop, thus making the situation more complex. The hair inside the PNS need not be from the perineal area alone, but can be broken ones from head and neck region or may be of non human origin as in case of bird feather from feather bed. The movement of the buttocks causes a negative pressure in the internatal cleft which causes the entry of the hair or skin debris into the swollen hair follicle. The intermammary PNS is a vexing problem for a young female which presents as a recurrent discharging sinus and induration as they find it difficult to cope with it due to social stigma or ignorance.

\section{Aim}

To assess the risk factors and treatment options for pilonidal sinus at a tertiary care centre with special reference to management of intermammary sinus.

\section{Material and Methods}

The patients presenting with PNS to the general surgery department at a tertiary care centre in north Malabar, Kerala from 2016 to 2018 were included in this study. Main presenting complaint was mucopurulent discharge, swelling in the peri anal and intermammary region, with features of inflammation and multiple openings in sacrococcygeal region. Sacrococcygeal PNS was mostly seen in males (30 males and 9 females). Those with abscess formation, incision and drainage were done. After the abscess healed, wide local excision was done under LA, and healing by secondary intention followed. All sacrococcygeal PNS without abscess formation were treated with $\mathrm{Z}$ plasty under local/ regional anaesthesia. All intermammary PNS was treated with wide local excision under general anaesthesia.

\section{Results}

49 cases of pionidal sinus (39 sacrococcygeal PNS and 10 intermammary) were included in this study. Nineteen wide local excision and twenty $\mathrm{Z}$ plasty were done for the sacrococcygeal PNS. For the 10 cases of intermammary sinuses wide local excision was performed. There was only one recurrence for the $\mathrm{Z}$ plasty and wide excision in the sacrococcygeal group and no recurrence in the intermammary group.

\begin{tabular}{|l|c|c|c|}
\hline Type Of PNS & $\begin{array}{c}\text { Total } \\
\text { Number }\end{array}$ & Surgery & Recurrence \\
\hline Sacrococcygeal & 39 & Z Plasty 20 & 1 \\
\hline Intrermammary & 10 & $\begin{array}{c}\text { Wide } \\
\text { Excision 19 }\end{array}$ & 1 \\
Excision & $\begin{array}{c}\text { Wide } \\
\text { Exion }\end{array}$ & 0 \\
\hline
\end{tabular}

Karidakis or Bascom methods were not used.

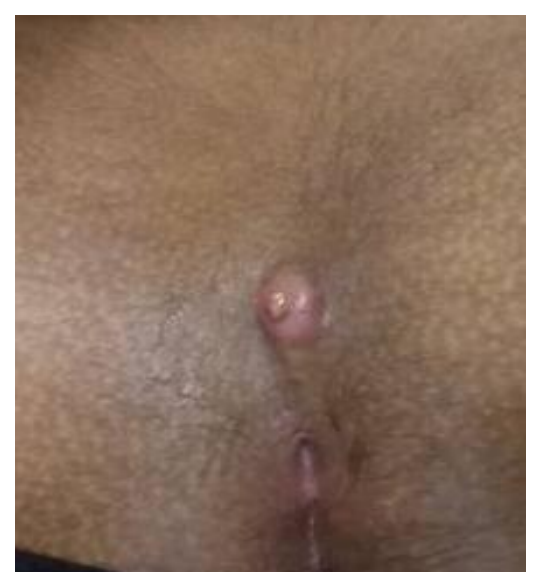

Fig 1. Sacrococcygeal pilonidal sinus with secondary abscess formation

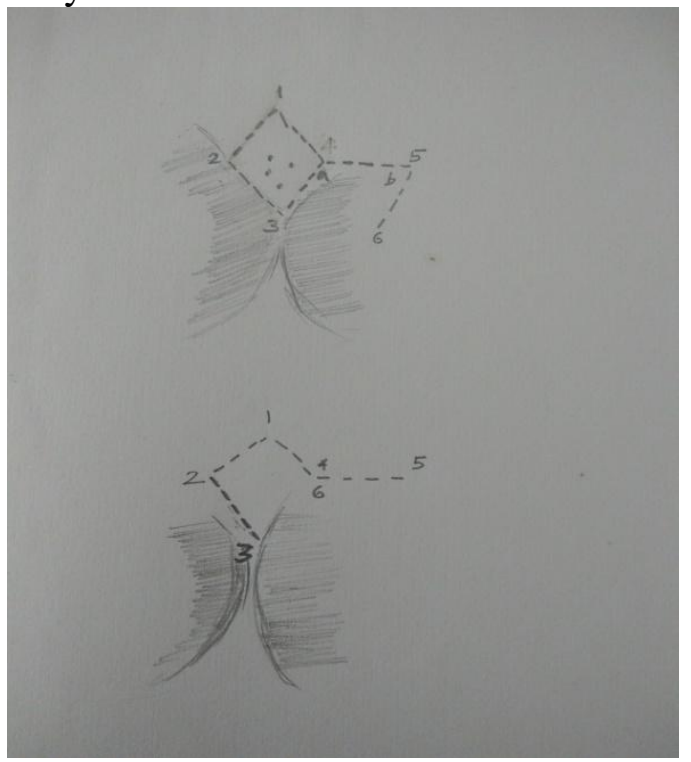

Fig 2. Limberg flap 


\section{Discussion}

The word pilonidal was coined by Herbert Mayo. ${ }^{[7]}$ Previously it was known as jeep bottom due to an increase in incidence of PNS in US army recruits at Vietnam who were using the jeep for travelling through the rough terrains. ${ }^{[8]}$ The term pilonidal sinus was coined by Hodges, where pilus means hair and nidus is nest. ${ }^{[9]}$ The intermammary sinus presents as a chronic discharging sinus with a linear indurated track towards the epigastric region, with local discoloration and tenderness. Wide excision and primary closure clearing al side tracks result in good healing with a better scar. Intermammary PNS where seen in young females of 14-18 years, with recurrent discharging sinus. At the onset they were misdiagnosed as folliculitis and was trated with oral antibiotic. It subsided only to recur at regular intervals. Being a young females, they were finding it difficult to perform their regular activities due to inferiority complex setting in all of them, due to fear of issues like discharge, disfigurement and smell. On diagnosing the condition this was explained to the patient and relatives and wide local excision with primary closure was undertaken. After cleaning and draping the area with betadine, methylene blue was injected into the sinus track. Wide excision of the track was done after removing the subcutaneous tissue. The intermammary cleft was reconstructed and the wound was closed with 2-0 vicryl and subcuticular 3-0 prolene. A $12 \mathrm{~F}$ drain was kept which was removed after 1 week. The wound was inspected on day 1,3,5 \&7.The subcuticular sutures were removed after 14 days. The wound healed with minimal scarring. This condition is commonly seen in hirsuit males which has a blind ending track lined with granulation tissue. They contain many broken pieces of hair and may have side tracks. When abscess forms the side tacks may rupture away from the main opening on to the skin surface. In the presence of such a separate external opening, the treatment becomes complex. ${ }^{[10]}$ [fig 1] Anil sunkari etal has described various options for the treatment of PNS. ${ }^{[1]}$ Management of PNS is frequently unsatisfactory. Ideal treatment modality rarely exists. If early excision of the pilonidal pit at the time of treatment of pilonidal abscess is done, it reduces the risk of subsequent sinus to the tune of $40 \% .^{[12]}$ In our series with wide local excision and primary closure the recurrence rate is only two cases in sacrococcygeal PNS and none in intermammary sinus. Limberg flap is said to be a better option for sacrococcygeal PNS as per Osmanoglu G et al. ${ }^{[13]}$ In 1946 Limberg developed a rhomboid flap for sacrococcygeal pilonidal sinus. The advantages of this flap was that, it was easy to perform, with sutures away from the midline giving rise to a tensionless flap of unscarred skin in the midline, which helps in good hygiene maintenance, reducing sweating maceration, erosions, and scar formation. A rhombic area of skin is marked over sacrococcygeal pilonidal sinus involving all midline and lateral pit. The long axis of the rhomboid in midline is marked as point $1-3,3$ being adjacent to perianal skin, 1 placed above so that all diseased tissues can be included in the excision. The line connecting points 2-4 transects the midpoint of 1-3 at right angles and is $60 \%$ of its length. Line $4-5$ is a direct continuation of the line $2-4$ and is of equal length to the incision $1-2$, to which it will be sutured after rotation. 5-6 is parallel to 3-4 and of equal length. After rotation, it will sutured to 1-4.

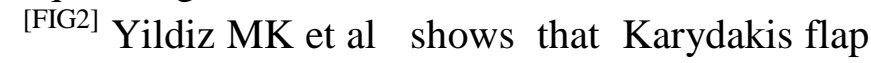
treatment for sacrococcygeal PNS is associated with low complication rate, shorter hospital stay, faster healing, and less morbidity. ${ }^{[14]}$ Fibrin glue, Bascoms technique are the other available options for the treatment of PNS. ${ }^{[15]}$

\section{Conclusion}

Pilonidal sinus especially intermammary sinus is a vexing problem for individuals especially 
young females. The changes in the hormonal balance during puberty is the triggering factor. Many treatment modalities are in the offering, suggesting that a complete cure may not be possible with any of those available. Wide local excision with primary closure or Z plasty are two viable options for this condition.

Conflicts of interest: There are no conflicts of interest

This is a non-funded project

Acknowledgements: We sincerely thank all the patients without whom this study would not have been possible.

\section{References}

1. Karydakis GE. Easy and successful treatment of pilonidal sinus after explanation of its causative process. ANZ Journal of Surgery. 1992 May 1;62(5):3859.

2. Gidwani AL, Murugan K, Nasir A, Brown $R$. Incise and lay open: an effective procedure for coccygeal pilonidal sinus disease. Irish journal of medical science. 2010 Jun 1;179(2):207-10.

3. Shabbir J, Chaudhary BN, Britton DC. Management of sacrococcygeal pilonidal sinus disease: a snapshot of current practice. International journal of colorectal disease. 2011 Dec 1;26(12):1619-20.

4. Bolandparvaz S, Moghadam Dizaj P, Salahi R, Paydar S, Bananzadeh M, Abbasi HR, Eshraghian A. Evaluation of the risk factors of pilonidal sinus: a single center experience. Turk J Gastroenterol. 2012 Oct 1;23(5):535-7.

5. Onder A, Girgin S, Kapan M, Toker M, Arikanoglu Z, Palanci Y, Bac B. Pilonidal sinus disease: risk factors for postoperative complications and recurrence. International surgery. 2012 Oct;97(3):224-9.

6. Oram Y, Kahraman F, KARıNCAOĞLU YE, Koyuncu E. Evaluation of 60 patients with pilonidal sinus treated with laser epilation after surgery. Dermatologic Surgery. 2010 Jan 1;36(1):88-91.

7. Coşkun A, Buluş H, Akıncı ÖF, Özgönül A. Etiological factors in umbilical pilonidal sinus. Indian Journal of Surgery. 2011 Jan 1;73(1):54-7.

8. Dogra S, Rao PP. Z-plasty a rational and effective technique for pilonidal sinus. Hellenic Journal of Surgery. $2014 \mathrm{Jul}$ 1;86(4):208-11.

9. Gidwani AL, Murugan K, Nasir A, Brown R. Incise and lay open: an effective procedure for coccygeal pilonidal sinus disease. Irish journal of medical science. 2010 Jun 1;179(2):207-10.

10. Senapati A, Cripps NP, Flashman K, Thompson MR. Cleft closure for the treatment of pilonidal sinus disease. Colorectal Disease. 2011 Mar1;13(3):333-6.

11. Sunkara A, Wagh DD, Harode S. Intermammary pilonidal sinus. International journal of trichology. $2010 \mathrm{Jul} ; 2(2): 116$.

12. Allen- Mersh TG. Pilonidal sinus: finding the right track for treatment. British Journal of Surgery. 1990 Feb 1;77(2):123-32.

13. Osmanoglu G, Yetisir F. Limberg flap is better for the surgical treatment of pilonidal sinus. Results of a 767 patients series with an at least five years follow-up period. Chirurgia. 2011 Jul 1;106(4):491-4.

14. Yildiz MK, Ozkan E, Odabaşı HM, Kaya B, Eriş C, Abuoğlu HH, Günay E, Fersahoglu MM, Atalay S. Karydakis flap procedure in patients with sacrococcygeal pilonidal sinus disease: experience of a single centre in Istanbul. The Scientific World Journal. 2013 May 14;2013.

15. Dudink R, Veldkamp J, Nienhuijs S, Heemskerk J. Secondary healing versus midline closure and modified Bascom natal cleft lift for pilonidal sinus disease. Scandinavian Journal of Surgery. 2011 Jun;100(2):110-3. 